\title{
Informational Resources for Innovations in Engineering Education
}

\author{
Leonid K. Bobrov ${ }^{1}$, Irbulat T. Utepbergenov ${ }^{2 *}$, and Victor B. Timofeev ${ }^{3}$ \\ ${ }^{1}$ Novosibirsk State University of Economics and Management, Kamenskaya str., 56, 630099, \\ Novosibirsk, Russia \\ ${ }^{2}$ Institute of Information and Computational Technologies, Pushkina str., 125, 050010, Almaty, \\ Kazakhstan \\ ${ }^{3}$ Bauman Moscow State Technical University, 2nd Baumanskaya str., 5/1, 105005, Moscow, Russia
}

\begin{abstract}
The high growth rates of digital data induce enterprises and organizations to pay more attention to information management. This is reflected in proper standards, frameworks and other normative and guidance documents. In these conditions the tasks of building the competencies of the specialists in managing business information and implementing the relevant training programs for engineering personnel are shown to be very relevant for developing the innovative economy. The list of information management standards is given, and the BiSL framework is highlighted to be important in outlining on the macrolevel the range of professional competencies of the personnel involved in information management processes. Since both Russia and Kazakhstan do not have yet full-fledged and thoroughly practice-approved competency standards for business information management specialists working in various applied fields, it is proposed to use European experience in creating a unified framework of professional ICT competence when developing educational programs. The determining role of world informational resources and technologies for their use in forming the basic infrastructure of innovations is substantiated. The informational resources specific to various staged of the innovation life cycle are characterized. The concise description of the project for creating the system of innovation informational support in the Republic of Kazakhstan is given. The requirements to the metainformation database containing descriptions of the informational resources are formulated. The introduction is given to the metadata format based on the «Dublin Core» which defines the composition and semantics of data elements. Within the framework of the system being developed it is proposed to build a procedure for searching the relevant information based on the use of production models.
\end{abstract}

\footnotetext{
* Corresponding author: i.utepbergenov@gmail.com
} 


\section{Introduction}

Achievement of progress in science and the creation of high-tech products, the availability of innovative research and development, the high level of training of engineering personnel are the most important indicators of the development of any modern state. An innovation economy is in high need of young people capable of generating new ideas, having high creative potential and deciding to get and engineering education in order to devote themselves to scientific and innovation activity. According to Professor N. Ford, in this activity the researcher aims at getting all the basic information of his filed of interest available in the world. N. Ford identifies the following motives for accessing information resources [1]:

- identification of existing points of view on the problem;

- determination of the «correctness» of any issue understanding;

- $\quad$ studying various views on the issue, allowing to reveal it as a whole;

- $\quad$ expansion of gained earlier knowledge;

- collecting information about the certain authors' writings;

- confirming the opinion on a particular issue;

- writing out quotes, making reviews, etc.

Incipient information needs can be satisfied by referring to a great number of information sources - research reports, patents, standards, scientific and technical literature, etc., including various types of electronic collections and digital data.

The IDC company, that regularly assesses the amount of created digital data, in its 2014 report states that by 2020 the digital universe size will reach 44 trillion gigabytes compared to 4,4 in 2013 . Besides, in 2013 only $22 \%$ of information can be considered as an object under analysis, i.e. as useful information, and only $5 \%$ is actually being analyzed. The volume of useful information is forecasted to increase to $35 \%$ by $2020[2,3]$.

High growth rates of digital data will lead to the fact that in 2020 each IT specialist will account for $1231 \mathrm{~GB}$ of information compared to $230 \mathrm{~GB}$ in 2014, i.e. there is more than fivefold growth, on condition that in 2020 the total number of such specialists will be 36 million people compared to 28 million in 2014 [3]. In a later report, IDC predicts global data to grow from 33 zettabytes in 2018 to 175 in 2025 [4], and this aggravates the situation.

Under these conditions, there is a significant increase of the role of the information manager, who must take a new approach, being focused on the value of the information itself and not on the information system cost $[5,6]$. Besides, IDC, while considering the issues of the digital universe in a country perspective, indicates determining the personnel's skills and experience required nowadays and for the future, as well as the development and implementation of particular plans for the training and retraining of personnel as one of the three most important tasks for enterprises in countries such as Russia, Germany, China, Japan, India, Brazil and others [7]. Another trend noted by the Gartner company is an overlap of the roles of an expert and an information manager. More and more people from the business sphere are coming into the information technology sphere, and they are taking responsibility for the information delivery infrastructure, not always having a rich IT experience [8].

In this regard, the competence building tasks for specialists in business information management and implementation of appropriate training programs for engineering personnel appear to be very relevant for the innovation economy development [9]. 


\section{Information management standards}

Western enterprises and organizations greatly attend to information management, which is reflected in the proper standards, frameworks and other normative and guidance documents. Among them one should note the CobiT information technology management and audit standard, the ITIL library of best IT practices, the ITSM IT service management framework, the ASL framework that reflects advanced experience in application services and the BiSL framework for business information management. A lot of various writings are dedicated to these documents, including many works posted on the Internet.

According to the BiSL recommendations [10], the main tasks of business information management are determining the requirements (needs) of a user organization, translating requirements into solutions regarding the following implementation (or change) of dataware, and also issuing tasks to service providers, monitoring and result assessment. Business Information Management at BiSL is closely related to enterprise application and IT management. Business processes and dataware are determined by the organization's policy administered by business management. Responsibilities are also appropriately distributed - business information management assists the business policy implementation through the information architecture, which provides dataware for business processes of the organization.

The business information management model, offered by the BiSL framework, includes 23 processes, combined into seven groups and decomposed into three levels - operational, managerial and strategic. The operational level processes refer to the current usage and changes of dataware, the managerial level includes the management of planning, quality, financing of dataware and relationship with IT contractors. Strategic level processes determine the prospects for dataware and the corresponding organization of its management. The processes of the "Usage Management" group are directed at supporting and controlling the effectiveness of current dataware.

Functionality management relates to the dataware engineering and implementation and enables the understanding of how it should change in the near future.

The implementation of the linking processes of the operational level is aimed to answer the question of why and how it is necessary to change dataware.

An essential part of a business information management system is personnel. Therefore, the BiSL framework seems very important for outlining at the macro level the range of professional competencies of personnel involved in information management processes.

\section{Competencies of a business information management specialist}

To support the own staff's competencies, many companies use internal employee training involving offsite teachers, extra training in business courses and ICT courses in universities, etc. In this conjuncture one of the promising ways to make up the deficit in engineering personnel with the necessary competencies for information management is the development of a master's training system and additional ICT education programs, when curricula and run-time programs of disciplines are developed cooperatively with representatives of professional community, based on the required by employers set of competencies, which a certain expert must have in order to carry out his tasks.

Since Russia does not have yet full-fledged and thoroughly practice-approved competency standards for business information management specialists working in various applied fields, it seems expedient to use the European experience in creating a unified framework of professional ICT competencies $[11,12]$ to develop proper ICT education programs. Version 2.0 of the European e-Competencies Framework can be noted to be 
adopted as the national standard of the Russian Federation, available at http://docs.cntd.ru/document/1200108055 "User guide for the application of the European e-Competencies Framework".

The third version of the European e-Competencies Framework (e-CF) includes 40 competencies being grouped into the following life-cycle state of information systems: A plan, B - build, C - run, D - enable, E - manage [13]. Steps B and C are considered the main ones, and D and $\mathrm{E}$ «run through» the main stages. For each competence, the possible (depended on the specifics of the educational program) levels of mastering it qualifications (from the first to the fifth) are determined.

Competencies are responsible for a certain list of knowledge and skills for each qualification level. Competencies, their components and proficiency levels reflect the profession profile. Currently, 23 profiles are described in e-CF, and an open interactive Internet resource [14] represented by a specialized software environment is created in order to automate the processes of building a set of requirements for any of 23 professional profiles (competencies, knowledge, skills necessary for a given qualification level).

In accordance with the European e-Competencies Framework, the mission of a business information management specialist is to manage and update existing applications and information services based on the needs, costs and plans approved by internal users in the interests of ensuring the guaranteed service quality for them and the satisfaction of their information needs. Accordingly, the main tasks of this specialist are following:

- management of the informational technology development in the business sector;

- anticipation of changes in the information system and their possible impact on the business;

- formalization of the tasks of developing the configuration of the information system, consolidation and stimulation of development processes;

- assessment of the relevance degree of information systems to areas of business activity and organization's business processes;

- building a knowledge base through understanding and using the organization's information system.

According to the European e-Competencies Framework, a specialist in business information management of the fifth qualification level (leading business information manager) must have the following competencies:

- A1 - IS and business strategy alignment;

- A3 - business plan development;

- D10 - information and knowledge management;

- $\quad$ E2 - project and portfolio management;

- $\quad$ E7 - business change management.

The European e-Competencies Framework is not a dogma; its purpose is declared as presenting a general description, recommendations, or so-called reference sets of ICT competencies that can be processed and adapted to different contexts of an ICT-using business. In accordance with this, the following fragment of the competency map of the leading business information manager (fifth qualification level according to e-CF), containing descriptions of competencies and revealing them to the level of specific knowledge and skills, is also proposed to be considered purely as an illustrative example (table 1). 
Table 1. Competency map fragment of a leading business information manager.

D10 competency - Information and Knowledge Management

Identifies dataflow, manages structured and unstructured information and considers information distribution policies. Creates information structure to enable exploitation and optimization of information for the benefit of business. Understands appropriate tools to be deployed to create, extract, maintain, renew and propagate business knowledge in order to capitalize from the information asset.

\begin{tabular}{|c|c|}
\hline $\begin{array}{l}\text { Knows/ aware of/ } \\
\text { familiar with }\end{array}$ & $\begin{array}{l}\text { - methods to analyze information and business processes } \\
\text { - ICT devices and tools applicable for the storage and retrieval of data } \\
\text { - challenges related to the size of data sets (e.g. big data) } \\
\text { - challenges related to unstructured data (e.g. data analytics) } \\
\text { - sources and methods of finding external information to solve current } \\
\text { and future business problems }\end{array}$ \\
\hline Is able to & $\begin{array}{l}\text { - process, formalize and satisfy the current and future needs in new } \\
\text { information and knowledge } \\
\text { - translate /reflect business behavior into structured information } \\
\text { - make information available } \\
\text { - apply data mining methods }\end{array}$ \\
\hline
\end{tabular}

\section{Information and innovation}

Modern innovative activity proceeds in the condition of sustainable development and expansion of digital bibliographic, factographic and full-text collections, involving for its creation the bodies of scientific and technical information, federal and industry libraries, universities, enterprises, associations and consortia of the innovation sphere, academic and industry scientific institutes, scientific and professional societies and unions, business information integrators, etc.

External information resources and technologies for their use play a decisive role in the formation of the basic infrastructure of innovations, since the competent use of them enables innovators to concentrate on solving professional problems, fully relying on writings reflecting the world existing developments in order to avoid solving again already solved problems $[15,16]$.

Information support of the innovation life cycle involves the integrated use of documentary and factual sources that reflect the following main thematic and specific aspects:

- $\quad$ scientific, technical and patent information, research reports and dissertations;

- materials of scientific conferences;

- anticipation and analytical information;

- market information;

- information on programs and research areas of the practical use of the fundamental research results;

- marketing information;

- information about potential investors and grant competitions;

- business and commercial information;

- legal and regulatory acts, standards and guides;

- economic information (including management), etc. 
It should be emphasized that the stages of generating an innovative idea and the initiation of a business idea are characterized by high uncertainty of goals and objectives, technological, semantic and organizational heterogeneity, and in some cases the territorial dispersion of the key participants and innovative activity resources involved in them. Therefore, information and analytical support for innovation is in demand not only, as it is universally adopted, for the stages of marketing, production, implementation and post-sale support, but also for the initial stages (of generation / initiation, research and development) of the innovation life cycle.

At the stage of generating an innovative idea and initiating a business idea, back-ground information is external information, contained in the results of analytical and marketing research, the which source, as a rule, is the external environment of a high-tech enterprise. It should be highlighted that today most of the new innovative solutions are becoming available to specialists, notably due to the integration of autonomous information systems. Regarding this, a trend is currently being noticed, which consists in the integration of disconnected information resources and the creation of unified information spaces both at the enterprise level and at the meso-, macro-, mega level.

A unified information space is a combination of databases and data banks, technologies for their management and use, information and telecommunication systems and networks operating on the basis of common principles and general rules ensuring the informational interaction of organizations and citizens, as well as the satisfaction of their information needs, grouping information resources into clusters of information, data, knowledge and competencies [16].

In turn, at the stage of fundamental research with the purpose of revealing new connections between phenomena in a specific subject area, understanding the laws in the ongoing natural and artificial processes in terms of their targeted use, it is necessary to extract information on this issue from the databases and to systemize it sub-sequent. For this stage of the life cycle, the databases should contain:

- data on the results of fundamental research in this subject field in terms of new knowledge, which may be the basis for applied research in the future;

- data on useful ideas, models obtained as a result of fundamental research in the subject and related fields.

For the stage of applied research, it is advisable to use new knowledge aimed at achieving practice-oriented goals and solving particular problems, notably connected with the model creation, manufacturing mock-ups, prototypes, pilot samples of a new technic and new promising technologies. At this stage, special calculations are per-formed for the purpose of analysis, evaluation and possible adjustment of ongoing research and, if necessary, the exclusion of unpromising ideas. The result is the development of technical specifications for the design of the desired full-scale object or product sample, technological recommendations, methods.

The applied research stage requires the extraction of information from information resources (for example, databases):

- $\quad$ on the results of search and applied research (writings) related to a specific subject field, in order to justify the generated ideas, conceptions, business models, etc.;

- on the practices of transforming the results of applied research into new samples of commercial products or their prototypes, models, mock-ups, experimental samples (express information, brochures, etc.);

- on the procedures and results of protecting research and development in related fields (regulatory documents, guidelines for executing the applications for intellectual property, patents, state registration certificates of computers, etc.).

Since the purpose of design projects is the development of technical documentation (technical, outline and detailed design, product sheets, etc.), as well as preliminary, running 
and serial tests of new product samples to confirm their reliability, operability, production and commercial use, in order to effectively ensure this stage, it is required to extract information from information resources (for example, databases):

- $\quad$ on the preparation and market entry of new engineering solutions;

- on engineering data management systems;

- on the security level of similar engineering solutions and their respective owners;

- on already used circuit layout and other design solutions;

- on the product components, technologies for their manufacture, assembly, installation, results of experiments and tests, materials and other elements, as well as their supply conditions;

- on possible counterparties and subcontractors, their competencies both at the stage of research and development, and at the subsequent stages of creating an innovative solution;

- on potential financing sources (budgetary resources of various levels, grants, own funds of the enterprise, financial means of the innovation team participants, cred-it resources, ventures, angel investors, etc.) and the conditions for their extension at various stages of research and development.

A special place is occupied by dataware at the stage of replication of innovation as an innovative product in the framework of industrial continuous production (single part, batch, mass). Industrial production is understood here as a process in which raw materials, basic materials or semi-finished products are transformed into an innovative product manufactured using industrial equipment and demanded on the market.

At this stage, there is a need in information regarding the analysis and assessment of market prospects for a new innovative solution, its compliance with current domestic and international standards, financial capabilities, new design and development practices for technological, organizational and management processes, preparation of all components for the production of a high-tech product.

A key condition for the effectiveness of dataware for the management of innovative business processes of an innovative enterprise is the speed excess of generalization and systematization of information over the speed of the innovation life cycle implementation stages. This is achieved not so much by improving the mechanisms and procedures for exchanging information between the subjects of innovative processes, as by improving the methods of converting information into knowledge or intellectual capital of an innovative enterprise.

Thus, each of the innovation life cycle stages requires dataware involving procedures for searching and processing particular information types: scientific and technical, patent, commercial, marketing, statistical, demographic, environmental, legal, information about competitors, information about potential consumers of innovations, etc.

\section{Project of creation an information support system for innovation activity of Kazakhstan}

Currently, the Institute of Information and Computational Technologies of the Ministry of Education and Science of the Republic of Kazakhstan (MES RK) is implementing a project dedicated to the creation of a republican system of information support of innovation activities considering the specifics of each stage of the innovation life cycle.

This project is aimed on creating an information and consulting environment to support the innovation activity of the Republic of Kazakhstan through information consulting and providing meta-information about world information resources that meet the challenges of expanded innovation production. 
Achieving this goal involves solving the following tasks:

- research on the specifics of the innovators' information needs at each stage of the innovation life cycle from the idea generation to the withdrawal of a product from the market;

- building a meta-information base on existing world information resources relevant to the tasks of each innovation life cycle stage (idea generation - research and development - design and development - experimental batch release - market launch - growth - saturation - recession - withdrawal from the market);

- development and commissioning of a specialized information searching system designed for situational orientation of innovation organizations in the global information space with the purpose of effective information support of innovation activities.

The solution of the tasks set covers the generalization and development of Kazakhstan, Russian and European experience in solving the problems of science and education dataware in relation to innovation as a modern type of activity with its own specific features.

The system should provide a search for information resources in the meta-information database by:

- a description of the practical situation (problems, tasks) by finding it directly or by reducing it to one of the typical ones presented in the system multi-level classifier;

- $\quad$ specified stage of the innovation life cycle;

- thematic classifier of information resources;

- an arbitrary query with expressions of keywords indicating the required search fields.

The meta-information database content should satisfy the following requirements:

- polythematic of the content;

- reflection of multispecies information sources;

- multi-country content;

- international nature of information resources;

- use of a single metadata model for all sources of information;

- the availability of detailed information about each information resource allowing to evaluate for what stage of the innovation life cycle it is advisable to use a resource, what is the record content and formats, vendors, access conditions, etc.

The system is designed for situational orientation of innovation organizations and innovators in the global information space with the purpose of effective information support of innovation activities.

When the user receives a list of detailed information resources as a result of the search and selects a particular resource (s), he can:

- get access to this resource by clicking on the corresponding hyperlink at the same place (if it is an open resource);

- familiarize himself with the access conditions and contact the vendor through the listed contact information for the agreement conclusion, or use the intermediary services of the meta-information base owner (if the resource is paid);

- in some cases, the user may be given the opportunity to study the demo version or get a trial access to some resources.

The central part in the system is the meta-information database containing descriptions of information resources. In terms of content, this base should provide for the possibility of giving the detailed information about each information resource to the user, which allows to decide at what stage of the innovation life cycle and in what practical situation it is advisable to use this resource. 
Dublin Core Metadata Elements were taken as the basis in the described information system when the metadata format was being developed. The Dublin Core consists of two levels. The first level is the Simple Dublin Core, the second is the Qualified Dublin Core. The composition of the first level elements was initially fixed in the international standard ISO 15836:2003 «Information and documentation - The Dublin Core metadata element set» [17].

In 2017, this standard was revised and replaced by ISO 15836-1:2017 standard «Information and documentation - The Dublin Core metadata element set - Part 1: Core elements» [18]. Terms of the second level, which includes qualifiers, encoding schemes, and sets of dictionary terms, are defined in the document «DCMI Metadata Terms» (Dublin Core Metadata Initiative Metadata Terms) [19]. As it is indicated in RFC 2413, the Dublin Core elements can be divided into three groups [20]:

1. Content - elements describing the resource content;

2. Intellectual Property - elements considered from the perspective of intellectual property;

3. Instantiation - elements related to a particular instance of a resource.

A running version of the metadata database structure used in the system of dataware of innovation activity of the Republic of Kazakhstan is presented below (Table 2).

Table 2. Metadatabase structure.

\begin{tabular}{|c|c|c|c|}
\hline $\begin{array}{c}\text { Data } \\
\text { elements }\end{array}$ & Data element function & Qualifier & Language \\
\hline \multirow{3}{*}{ Coverage } & \multirow{3}{*}{$\begin{array}{l}\text { Characteristics of the } \\
\text { resource location and time } \\
\text { duration }\end{array}$} & CNTR - country & Classification \\
\hline & & $\mathrm{RC}$ - retrospective coverage & Numerical \\
\hline & & CCV - country coverage & Classification \\
\hline \multirow{4}{*}{ Date } & \multirow{4}{*}{$\begin{array}{l}\text { The date of certain event } \\
\text { in the resource lifecycle }\end{array}$} & CRT - created & Data format \\
\hline & & VLD - valid & Data format \\
\hline & & AVL - available & Data format \\
\hline & & MODIF - modified & Data format \\
\hline \multirow{4}{*}{$\begin{array}{l}\text { Descrip- } \\
\text { tion }\end{array}$} & \multirow{4}{*}{$\begin{array}{l}\text { Description of the } \\
\text { resource content }\end{array}$} & $\begin{array}{c}\mathrm{TC}-\text { table of contents } \\
\text { (composition of the resource) }\end{array}$ & Free text \\
\hline & & $\mathrm{AB}-$ abstract & Free text \\
\hline & & PPT - presentation & \\
\hline & & $\mathrm{CO}-$ commentary & Free text \\
\hline \multirow{2}{*}{ Format } & \multirow{2}{*}{$\begin{array}{c}\text { Resource data } \\
\text { presentation format }\end{array}$} & EXT- extent of the resource & Free text \\
\hline & & MEDI - media-type & Classification \\
\hline \multirow{2}{*}{ Language } & \multirow{2}{*}{ Resource language } & $\begin{array}{c}\text { ISO_639 - two-letter language } \\
\text { code }\end{array}$ & Classification \\
\hline & & $\begin{array}{c}\text { ISO_3166 two-letter country } \\
\text { code }\end{array}$ & Classification \\
\hline \multirow{2}{*}{ Publisher } & \multirow{2}{*}{$\begin{array}{l}\text { Organization responsible } \\
\text { for accessing the resource }\end{array}$} & CNTR - country & Classification \\
\hline & & ORG - organization & Free text \\
\hline \multirow{2}{*}{ Relation } & \multirow{2}{*}{$\begin{array}{l}\text { Related (similar) } \\
\text { resources that fully or } \\
\text { partially cover this } \\
\text { resource }\end{array}$} & $\mathrm{RR}$ - related (similar) resources & $\begin{array}{l}\text { Use of authority } \\
\text { files is possible }\end{array}$ \\
\hline & & $\mathrm{CO}$ - commentary & Free text \\
\hline
\end{tabular}


Table 2. (Continued) Metadatabase structure.

\begin{tabular}{|c|c|c|c|}
\hline $\begin{array}{c}\text { Data } \\
\text { elements }\end{array}$ & Data element function & Qualifier & Language \\
\hline \multirow{4}{*}{ Rights } & \multirow{4}{*}{$\begin{array}{l}\text { Information about rights } \\
\text { of using and managing the } \\
\text { resource }\end{array}$} & $\begin{array}{l}\text { LIC - license (right to manage } \\
\text { the resource) }\end{array}$ & Free text \\
\hline & & PIS - intellectual property right & Free text \\
\hline & & AVP - author's right & Free text \\
\hline & & $\mathrm{DR}$ - other property rights & Free text \\
\hline \multirow[t]{2}{*}{ Source } & \multirow{2}{*}{$\begin{array}{c}\text { A related resource from } \\
\text { which a given resource } \\
\text { can be obtained in whole } \\
\text { or in part }\end{array}$} & $\mathrm{RV}$ - related vendors & $\begin{array}{l}\text { Use of authority } \\
\text { files is possible }\end{array}$ \\
\hline & & $\mathrm{CO}$ - commentary & Free text \\
\hline \multirow{5}{*}{ Subject } & \multirow{5}{*}{$\begin{array}{l}\text { Theme, subject or content } \\
\text { of the resource }\end{array}$} & KW - keywords & Descriptor \\
\hline & & $\begin{array}{c}\mathrm{CC}-\text { resource classification } \\
\text { codes }\end{array}$ & Classification \\
\hline & & LCS - life cycle stage & Classification \\
\hline & & $\begin{array}{c}\text { RS - relevance of a practical } \\
\text { situation (problem being } \\
\text { solved) }\end{array}$ & Classification \\
\hline & & $\mathrm{TA}-$ target audience & Classification \\
\hline \multirow{2}{*}{ Title } & \multirow{2}{*}{$\begin{array}{l}\text { Known name of the } \\
\text { resource }\end{array}$} & ABBR - abbreviations & Free text \\
\hline & & TRNS - translations & Free text \\
\hline \multirow{3}{*}{ Type } & \multirow{3}{*}{ Resource category } & RT - resource type & Classification \\
\hline & & IT - information type & Classification \\
\hline & & $\begin{array}{l}\text { SCI - species category } \\
\text { information }\end{array}$ & Classification \\
\hline
\end{tabular}

In the proposed version of the metadata base structure, the elements correspond to the Dublin Core standard, and the list of qualifiers relevant to the current problem has been expanded. It makes sense to comment on some of the positions presented in the table.

1. The Coverage data item. The qualifiers of the Coverage data element indicate the spatial localization of the described resource (country) - CNTR, retrospective coverage (period, date or date range) - RC, country coverage - CCV.

2. The Relation data item. The RR qualifier specifies related (similar) resources (for example, for the RSCI (Russian Science Citation Index), the RSCI database may be indicated as a related resource).

3. The Publisher data element characterizes the responsibility for providing a resource to users (this may be an individual, organization, or service). Publisher data item qualifiers specify the organization responsible for the provision of the resource - ORG, and the country of the organization's location - CNTR.

4. The Source data element answers the question from which other resource, or from which other vendor this resource can be obtained in whole or in part.

5. The Subject data element characterizes the subject content of the resource. The LCS qualifier is filled in when indexing an information resource and indicates at what stage of an innovation product life cycle this resource can be useful. The following stages of the life cycle are provided: 
- idea generation and filtering (innovation product idea generation, product concept development, marketing concept development, analysis of production and marketing opportunities);

- research and development;

- design and development;

- pilot production (production and testing of a prototype; design, technology and organization of preparatory production; production of a product pilot batch; sales analysis, product finalization, marketing concepts, etc.);

- industrial production (deployment of a full-scale production and marketing system);

- market launch (product and company promotion, sales analysis, etc.);

- growth (market expansion, monitoring and price adjustment, supporting advertising, other events);

- saturation (retention of position and market share, intensification of marketing actions, profit due to cost reduction);

- recession (analysis of opportunities and options for curtailing production, searching for new sales markets, advertising in new segments, reducing costs while reducing sales).

The RS Qualifier. A list of typical practical situations is generated in the system and the user is given the opportunity to select one of them to simplify the search procedure. Examples of practical situations: technology search, selection of suppliers, market analysis, marketing organization, etc.

The TA qualifier indicates the target audience of the information resource (for example, researchers, marketers, etc.).

6. The Type data item. Qualifiers are provided for this element, allowing to specify:

- resource type (RT) - thematic portal, electronic journal, database, etc.;

- information type (IT) - factual, bibliographic, full-text, mixed, etc.;

- species category of information (SCI) - scientific and technical, patent, marketing, etc.).

One of the searching modes of resources that correspond to the practical situation of the user is a search through a system of classifiers, when, for example, the life cycle stage, the required topic, the current problem, etc. are specified. The implementation of this opportunity can be carried out using production models of two types:

1) IF (A = TRUE) THEN B (products with a deterministic core);

2) IF (A = TRUE) THEN with a lot of confidence $\mathrm{B}$ (products with a nondeterministic core),

where A - a logical expression of the form $<$ condition $1>\&<$ condition $2>\& \ldots \&<$ condition $\mathrm{n}>$, B - a list of recommended information resources.

\section{Conclusion}

The training of engineering personnel as drivers for the development of innovation economics should propose students to acquire the knowledge and skills in the field of innovation dataware. Therefore, the formation of the information infrastructure for supporting innovation is relevant both from a practical and educational point of view.

The combined innovation productivity of enterprises and organizations seems to be directly dependent on the information support quality for innovations at each stage of their life cycle. In turn, improving the quality of information support requires both attracting a wide range of external information resources and creating a unified technological 
environment for navigation, storage, retrieval, processing and provision of information based on distributed data processing networks.

Considering the enormous volumes of world digital data and the variety of possible ways to access information relevant to the challenges of innovation, it is advisable to build specialized information systems that provide navigation in the global information space and selection of the most appropriate way to access the proper resources. Such systems can be built based on the formation of a meta database containing a multiaspects description of information resources, considering the specifics of information needs typical to each stage of the innovation life cycle.

\section{References}

1. N. Ford, Psychological determinants of information needs: a small-scale study of higher education students, Journal of librarianship, 18(1), pp. 47-62 (1986). DOI:10.1177/096100068601800103

2. M. Zwolenski, L. Weatherill, The digital universe: Rich data and the increasing value of the internet of things, Australian Journal of Telecommunications and the Digital Economy, 2(3), p. 47 (2014).

3. V. Turner, J.F. Gantz, D. Reinsel, S. Minton, The digital universe of opportunities: Rich data and the increasing value of the internet of things, IDC Analyze the Future, 16 (2014).

4. D. Reinsel, J. Gantz, J. Rydning, Data age 2025: The evolution of data to life-critical don't focus on big data. Focus on the data that's big sponsored by seagate the evolution of data to life-critical don't focus on big data (2017).

5. C. Bell, Finding value with Information Management [Electronic resource], C. Bell University of Waterloo: [website]. [17.06.2015]. - Access mode: https://uwaterloo.ca/information-systems-technology/blog/post/finding-valueinformation-management\#d, free (date of access: 23.11.2015). - Screen title.

6. I. Utepbergenov, L. Bobrov, I. Medyankina, Z. Rodionova, S. Toibaeva, About the Concept of Information Support System for Innovative Economy in the Republic of Kazakhstan. International Conference on Information Technologies, Springer, Cham, pp. 515-526 (2019). DOI:10.1007/978-3-030-12072-6_42

7. The Digital Universe of Opportunities: Rich Data and the Increasing Value of the Internet of Things // EMC Digital Universe with Research \& Analysis by IDC: [website]. - Access mode: https://www.emc.com/leadership/digitaluniverse/2014iview/high-value-data.htm, free (date of access: 23.11.2017). - Screen title.

8. Neil Chandler, Bill Hostmann, Nigel Rayner, Gareth Hersche, Gartner's Business Analytics Framework // Gartner, Inc.: [website]. Access mode: https://www.gartner.com/imagesrv/summits/docs/na/businessintelligence/gartners_business_analytics_219420.pdf, free (date of access: 21.12.2017). - Screen title.

9. B. Kubekov, L. Bobrov, E. Savelyeva, V. Naumenko, A. Utegenova, Projectcompetent paradigm of knowledge representation of the three-level engineering education system // CEUR Workshop Proceedings: [website]. Access mode: http://ceur-ws.org/Vol-2344/paper12.pdf , free (date of access: 5.11.2019). - Screen title. 
10. Business information management: An introduction to BiSL https://www.maise.nl/an_introduction_to bisl_v10\%20\%20Machteld\%20Meijer\%20en\%20Louk\%20Peters\%20-\%20.pdf

11. A common European framework for ICT Professionals in all industry sectors [Electronic resource] // The European e-Competence Framework: [website]. Access mode: http://www.ecompetences.eu, free (date of access: 3.11.2015). - Screen title.

12. O. Dolinina, L. Bobrov, A. Brovko, D. Cherchimtseva, Enhancement of ITprofessional education: Russian-Kazakh network of the IT-training centers, Proceedings of the International Conference IMS-2017, ACM, pp. 90-93 (2017). DOI: $10.1145 / 3143699.3143742$

13. e-CF overview [Electronic resource] // The European e-Competence Framework: [website]. Access mode: https://www.ecompetences.eu/e-cf-overview/

14. e-CF 3.0 Profiling tool on-line [Electronic resource] // The European e-Competence Framework: [website]. Access mode: http://www.ecompetences.eu/e-cf-3-0-and-ictprofiles-on-line-tool/

15. L.K. Bobrov, I.P. Medyankina, On the Influence of the Conceptual Apparatus on Setting the Tasks of Information Support of Innovation Activities, Automatic Documentation and Mathematical Linguistics, 52(2), pp. 97-107 (2018). DOI:10.3103/S000510551802005X

16. L.K. Bobrov, I.P. Medyankina, Mathematical Model of Data Processing System for Information Support of Innovative Cluster Works, International Conference on Computational and Information Technologies in Science, Engineering and Education, Springer, Cham, pp. 64-70 (2018). DOI:10.1007/978-3-030-12203-4_7

17. Dublin Core Metadata Initiative [Electronic resource] // Dublin Core Metadata Initiative: innovation in metadata design, implementation \& best practice: [website]. Access mode: http://www.dublincore.org/specifications/dublin-core/dces/2003-06-02/, free (date of access: 26.04.2019). - Screen title.

18. Information and documentation - The Dublin Core metadata element set - Part 1: Core elements: ISO 15836-1:2017 [Electronic resource] // ISO. Online Browsing Platform (OBP): [website]. - Access mode: https://www.iso.org/obp/ui/\#iso:std:iso:15836:-1:ed1:v1:en, free (date of access 21.05.2019). - Screen title.

19. Dublin Core Metadata Initiative [Electronic resource] // Dublin Core Metadata Initiative: innovation in metadata design, implementation \& best practice: [website]. Access mode: http://www.dublincore.org/specifications/dublin-core/dcmi-terms/, free (date of access: 26.04.2019). - Screen title.

20. S. Weibel, J. Kunze, C. Lagoze, M. Wolf, Dublin core metadata for resource discovery, Internet Engineering Task Force RFC, 2413(222), 132 (1998). 